\title{
Prevalence of Pulmonary tuberculosis and immunological profile of HIV co-infected patients in Northwest Ethiopia
}

\author{
Yitayih Wondimeneh", Dagnachew Muluye ${ }^{2^{*}}$ and Yeshambel Belyhun ${ }^{3}$
}

\begin{abstract}
Background: In sub-Saharan Africa, as high as 2/3 of tuberculosis patients are HIV/AIDS co-infected and tuberculosis is the most common cause of death among HIV/AIDS patients worldwide. Tuberculosis and HIV co-infections are associated with special diagnostic and therapeutic challenges and constitute an immense burden on healthcare systems of heavily infected countries like Ethiopia. The aim of the study was to determine the prevalence of pulmonary tuberculosis and their immunologic profiles among HIV positive patients.

Methods: A cross sectional study was conducted among adult HIV-positive patients attending HIV/AIDS clinic of Gondar University Hospital. Clinical and laboratory investigations including chest $\mathrm{x}$-ray and acid fast staining were used to identify tuberculosis cases. Blood samples were collected to determine CD4+ lymphocyte count. A structured questionnaire was used to collect socio-demographic characteristics of study subjects. The data was entered and analyzed using SPSS version 16 software.

Results: A total of 400 HIV positive study participants were enrolled. Thirty (7.5\%, 95\%Cl: 5.2-10.6\%) of the study participants were found to have pulmonary tuberculosis. In multivariate analysis, only CD4+ lymphocyte count $(\mathrm{AOR}=2.9 ; 95 \% \mathrm{Cl}: 1.002-8.368)$ was found to be independently associated with tuberculosis-HIV co-infection. Individuals who had advanced WHO clinical stage were also statistically significant for co-infection. The mean CD4+ lymphocyte count of HIV mono-infected participants were $296 \pm 192$ Cells/mm3 and tuberculosis-HIV co-infected patients had mean CD4+ lymphocyte count of $199 \pm 149$ Cells $/ \mathrm{mm} 3$ with p value of 0.007 .

Conclusions: We found high prevalence of tuberculosis-HIV co-infection. Lower CD4+ lymphocyte count was found to be the only predicting factor for co-infection. Early detection of co-infection is very necessary to prolong their ART initiation time and by then strengthening their immune status.
\end{abstract}

\section{Background}

Tuberculosis (TB) and human immune deficiency virus (HIV) infections are two major public health problems in many parts of the world. The prevalence of TB-HIV Co-infection is higher worldwide and $90 \%$ of these coinfected cases live in developing nations [1-3]. Tuberculosis is the most common opportunistic disease and cause of the death for those infected with HIV [3]. Similarly, HIV infection is one of the most important risk factors associated with an increased risk of latent TB

\footnotetext{
*Correspondence: fetenemulu24@gmail.com

${ }^{2}$ Department of Medical Microbiology, School of Biomedical and Laboratory Sciences, College of Medicine and Health Sciences, University of Gondar, P.O. Box 196, Gondar, Ethiopia

Full list of author information is available at the end of the article
}

infection progressing to active TB disease $[4,5]$. In persons infected with TB only, the lifetime risk of developing TB ranges between 10\% and 20\% [6,7]. However in persons who have been co-infected with TB and HIV, the annual risk can exceed 10\% [8-10].

An estimated 1.37 million HIV positive TB patients were diagnosed globally in 2007, and around $80 \%$ of them live in sub-Saharan Africa [11]. Tuberculosis and HIV co-infections are associated with special diagnostic and therapeutic challenges and constitute an immense burden on healthcare systems of heavily infected countries like Ethiopia [12].

Unlike other opportunistic infections which occur at CD4+ lymphocyte count below 200/mm3, active TB occurs throughout the course of HIV disease [13].

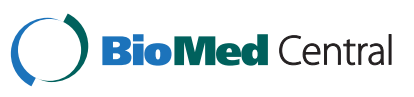


Clinical presentation of TB in HIV-infected individuals depends on the level of immunosuppression resulting from HIV infection. In patients with relatively intact immune function (CD4+ lymphocyte count $>200 / \mathrm{mm} 3$ ), pulmonary tuberculosis (PTB) is more frequently seen than extra pulmonary TB $[14,15]$.

Ethiopia is among the countries most heavily affected by the HIV and TB. The World Health Organization (WHO) has classified Ethiopia 7th among the 22 high burden countries with $\mathrm{TB}$ and HIV infection in the world [16].

It is recognized that joint TB-HIV interventions will clearly require additional funding to improve both TB and HIV program performance and coverage, increase testing and counseling, prevent mother to child transmission of HIV infection, provide community home based care for people living with HIV/AIDS and provide antiretroviral treatment. Despite this needs, there is no adequate and recent data in Ethiopia especially in this study area. Therefore, the aim of this study was to determine the prevalence of PTB among pre-antiretroviral treatment (ART) HIV positive patients and their immunologic profiles which is important for health professionals and policy makers to make evidence based decisions.

\section{Methods}

\section{Study design, period and setting}

A cross sectional study was conducted from March 27 to May 30, 2011 at Gondar University Hospital, Northwest Ethiopia. Gondar University Hospital is a teaching referral hospital located $720 \mathrm{~km}$ North West of Addis Ababa. It is the only referral hospital for North West Ethiopia serving a population of about 5 million coming from different geographical locations surrounding it. The hospital provides inpatient and outpatient services, including care and treatment for TB and HIV/AIDS patients with ARTs. Patients being evaluated for ART initiation undergo a routine medical examination, including screening for TB disease and other opportunistic infections.

\section{Source population and Study participants}

The source populations for this study were all HIV positive individuals who have the access to be served in Gondar University Hospital. The study participants were all ART naive HIV positive adult individuals who have visited ART clinic at Gondar University Hospital during the study period. A total of 422 subjects were enrolled in the study considering 95\% confidence, 5\% margin of error, $50 \%$ of prevalence of TB (since there was no previous estimate of TB among HIV infected individuals in the area) and $10 \%$ contingency by using single proportion formula [17]. Study subjects were selected using systematic sampling technique from patient's record in HIV/AIDS clinic by taking patients registered in every $6^{\text {th }}$ interval. Those
ART naive adult HIV positive individuals who gave informed consent and enough amount of blood sample were included but Individuals who were on ART and those with known chronic illnesses like diabetes mellitus and hypertension were excluded from the study.

\section{Data collection procedures}

All subjects underwent TB screening which include: (1) symptom screening and physical examination, (2) patients having sputum production and clinical manifestations were requested to provide three sputum specimens (spot-morning-spot) for smear microscopy, and (3) chest radiography. Study participants were interviewed about the presence of clinical manifestations of TB. Sociodemographic characteristics and other related risk factors were collected using structured questionnaire by trained nurses and physical examination was done by physicians. Posterior and anterior chest $\mathrm{x}$-ray (CXR) was done for patients having sputum production and clinical manifestations and interpreted. All patients having sputum production and clinical manifestations provided 3 sputum samples for smear examinations (spot-early morningspot). Sputum was collected in a plastic leak-proof container and smear was done for acid fast staining using a direct Ziehl-Neelson (ZN) technique [18]. Five milliliter of venous Blood was aseptically collected in ethylene diamine-tetra-acetic acid (EDTA) tubes for CD4+ lymphocyte count. The CD4+ lymphocyte count was done by BD FACS count flow cytometry machine [19]. The daily, weekly and monthly maintenance of the $\mathrm{BD}$ FACS count flow cytometry was done according to the instruments manual and quality control for both the reagent and the machine was done daily.

\section{Case definitions}

Smear positive PTB was defined as one or more sputum smear examinations positive for acid fast bacilli (AFB). Smear-negative PTB was also defined as three sputum smear examinations negative for AFB but with clinical and radiographic abnormalities consistent with active tuberculosis [20].

\section{Data analysis}

Data were checked for completeness, cleaned manually and entered and analyzed using SPSS version 16 statistical software (SPSS Inc. Chicago, USA). Data were summarized using frequency tables. Backward Stepwise logistic regression model was fitted to identify different determinants of TB-HIV co-infection. Standard techniques for model checking, including the Hosmer-Lemeshow goodness of fit test, were carried out to determine the adequacy of the regression model. Statistical significance was inferred at P-value $<0$.05. Mean plus standard deviation with $95 \%$ confidence interval $(\mathrm{CI})$ was also used for 
Table 1 Socio-demographic characteristics of HIV positive study participants at University of Gondar Teaching Hospital, North West Ethiopia, 2011

\begin{tabular}{llcc}
\hline Characteristics & & Frequency & $\%$ \\
\hline Age & $18-29$ & 128 & 32.0 \\
& $30-39$ & 167 & 41.8 \\
& $40-49$ & 78 & 19.5 \\
Sex & 50 and above & 27 & 6.8 \\
Residence & Male & 122 & 30.5 \\
& Female & 278 & 69.5 \\
Marital status & Urban & 335 & 83.8 \\
& Rural & 65 & 16.2 \\
& Single & 75 & 18.8 \\
& Married & 200 & 50.0 \\
& Divorced & 82 & 20.5 \\
Educational status & Widowed & 43 & 10.8 \\
& Illiterate & 151 & 37.8 \\
& Elementary school & 96 & 24.0 \\
& High school & 112 & 28.0 \\
& Certificate and above & 41 & 10.2 \\
& Government employed & 58 & 14.5 \\
& Merchants & 42 & 10.5 \\
& Housewife and daily laborer & 279 & 69.8 \\
Occupational status & 7 & 1.8 \\
& Commercial sex workers & 14 & 3.5 \\
& & &
\end{tabular}

continuous variables and the difference in means was compared with independent-sample t-test.

\section{Ethical considerations}

Ethical issues were approved by ethical review committee of Department of Microbiology, Immunology and
Parasitology, College of Medicine and Health sciences, University of Gondar. Oral and verbal informed consent was obtained from the patients prior to enrolment. Patients having tuberculosis were directed to TB/HIV clinic for treatment.

\section{Results}

A total of 422 study subjects were sampled but 22 of them were not included because of absence of sputum production for microscopy. Out of 400 study participants, $122(30.5 \%)$ were males (with mean age of $37 \pm 9$ years) and $278(69.5 \%)$ were females (mean age of $32 \pm 9$ years) with male to female ratio of $0.4: 1$. The lowest and the highest age of the study participants were 18 and 70 years respectively. Three hundred thirty five (83.8\%) of study participants were from urban and the rest were from rural areas. Half of the participants (50\%) were married and 151 (37.8) were illiterate. Out of the total study participants, $279(69.8 \%)$ were housewives and daily laborers [Table 1].

\section{Tuberculosis-HIV co-infection}

Thirty (7.5\%, 95\%CI: 5.2-10.6\%) of the study participants were found to have PTB. Of these TB-HIV co-infected cases, 19 (63.3\%) were smear negative PTB. The majority of PTB cases 27 (90\%) were found to have chest radiological abnormalities consistent with active PTB and about $93.3 \%$ of co-infected study subjects were found to have constitutional symptoms; cough of $>2$ weeks duration, fever, night sweat and weight loss. The majority of participants $263(65.7 \%)$ were in WHO clinical stage of I followed by WHO clinical stage II 65 (16.3\%) and WHO clinical stage III 61 (15.3\%). Only 11 (2.8\%) study participants were found to be in WHO clinical stage IV [Table 2].

Table 2 Clinical and immunological profile of study participants at University of Gondar Teaching Hospital, North West Ethiopia, 2011

\begin{tabular}{|c|c|c|c|c|}
\hline \multirow[t]{2}{*}{ Variables } & & \multicolumn{2}{|c|}{ Pulmonary tuberculosis } & \multirow[t]{2}{*}{ Total } \\
\hline & & Yes (TB-HIV) & No (HIV alone) & \\
\hline \multirow[t]{2}{*}{ WHO clinical stage $(n=72)$} & Stage III & $21(34.4 \%)$ & $40(65.6 \%)$ & $61(84.7 \%)$ \\
\hline & Stage IV & $9(81.8 \%)$ & $2(18.2 \%)$ & $11(15.3 \%)$ \\
\hline \multirow[t]{2}{*}{ Smear positive } & Yes & $11(100 \%)$ & $0(0 \%)$ & $11(2.7 \%)$ \\
\hline & No & $19(4.9 \%)$ & $370(95.1 \%)$ & $389(97.3 \%)$ \\
\hline \multirow[t]{2}{*}{ Chest radiography } & Suggestive & $27(100 \%)$ & $0(0 \%)$ & $27(6.7 \%)$ \\
\hline & Not Suggestive & $3(0.8 \%)$ & $370(99.2 \%)$ & $373(93.3 \%)$ \\
\hline \multirow[t]{2}{*}{ Constitutional symptoms (cough, fever, night sweat weight loss) } & Yes & $28(22.6 \%)$ & $96(77.4 \%)$ & 124 (31\%) \\
\hline & No & $2(0.7 \%)$ & $274(99.3 \%)$ & $276(69 \%)$ \\
\hline \multirow[t]{3}{*}{ CD4+ Lymphocyte count } & $<200$ Cells/mm3 & $16(11.3 \%)$ & $126(88.7 \%)$ & $142(35.5 \%)$ \\
\hline & 200-349Cells/mm3 & $8(5.6 \%)$ & $135(94.4 \%)$ & $143(35.8 \%)$ \\
\hline & $\geq 350$ Cells $/ \mathrm{mm} 3$ & $6(5.2 \%)$ & 109 (94.8\%) & 115 (28.7\%) \\
\hline
\end{tabular}




\section{Immunological profile of study subjects}

The majority of study participants 285 (71.3\%) had CD4+ lymphocyte count of less than 349 Cells/mm3 and 115 (28.7\%) of study participants had CD4+ lymphocyte count of greater than or equal to 350 Cells $/ \mathrm{mm} 3$ [Table 2]. Sixteen $(53.3 \%)$ of co-infected patients were found to have CD4+ lymphocyte count less than 200 Cells/mm3. The mean CD4+ lymphocyte count of HIV mono-infected participants was $296 \pm 192$ Cells/mm3 and TB-HIV coinfected patients had mean CD4+ lymphocyte count of $199 \pm 149$ Cells/mm3 with P-value of 0.007 .

\section{Predictors of TB-HIV co-infection}

In multivariate analysis, only CD4+ lymphocyte count was found to be independently associated with TB-HIV co-infection. Individuals who had $\mathrm{CD} 4+$ lymphocyte count of $<200$ Cells $/ \mathrm{mm} 3$ were 2.9 (95\% CI: 1.002-8.368) times more likely to be co-infected than individuals who had CD4+ lymphocyte count of $\geq 350$ Cells $/ \mathrm{mm} 3$. Though the independent effect (in multivariate analysis) of WHO clinical stage is not determined because of zero cells of stage I and stage II, individuals who had a WHO clinical stage of IV were 8.6 (95\% CI:1.69-43.34) times more likely to be co-infected compared to individuals who had a WHO clinical stage of III in crude analysis. Government employed individuals were $56 \%$ less likely to be coinfected compared to commercial sex worker [Table 3].

\section{Discussion}

The ever-increasing prevalence of PTB in Ethiopia has been made worse by the increasing incidence of HIV/ AIDS. In this study, we noted higher prevalence of PTB (7.5\%) among HIV positive pre-ART patients. This finding is in line with studies conducted in Nigeria (7.8\%) and Tanzania $(8.5 \%)$ [21, 22]. However, the finding of this study was lower compared to studies conducted in Cambodia (12\%), Nigeria (32.8\%) and India (19.2\%) [23-25]. The presence of this difference could be explained by the fact that this study considers only PTB but not other forms of TB. Our study was also restricted to preART HIV positive patients in which relatively strong immunity might have contributed for lower prevalence of TB-HIV co-infection since opportunistic infections are more prevalent during compromised immune status.

Of pulmonary tuberculosis co-infected cases, 19 (63.3\%) were smear negative. This result is almost in line with study findings of Tanzania (60\%), India (68.9\%) and Ethiopia (58\%) [22, 25, 26] but lower than what was reported from Nigeria (82.5\%) [21]. This difference might be due to the variation in concentration of acid fast bacilli in the sputum and the rate of caseation necrosis.

Tuberculosis can occur at any stage of HIV disease, and its manifestations depend largely on the level of immunosuppression. Early during HIV disease, symptoms and signs are similar to those in HIV-uninfected persons: the lungs are most commonly affected, with cough, fever, and respiratory signs along with radiographic lesions, often with cavitations [27]. In the present study, $93.3 \%$ of coinfected study subjects were found to have constitutional symptoms; cough of greater than two weeks duration, fever, night sweat and weight loss. Radiological abnormalities suggestive of PTB are also witnessed in $90 \%$ of coinfected study subjects. This result was in parallel with previous findings used for TB diagnosis and treatment guideline development.

The mean CD4+ lymphocyte count of HIV monoinfected participants was $296 \pm 192$ Cells $/ \mathrm{mm} 3$ and TBHIV co-infected patients had mean CD4+ lymphocyte count of $199 \pm 149$ Cells $/ \mathrm{mm} 3$. The mean difference was statistically significant with $\mathrm{p}$ value of 0.007 . Sixteen (53.3\%) of co-infected patients were found to have CD4+ lymphocyte count of less than 200 Cells/mm3. As CD4+ lymphocyte count decreased the body defense mechanism will be overwhelmed by various opportunistic infections. In multivariate analysis, CD4+ lymphocyte count was found to be independently associated with TB/HIV coinfection. Individuals who had CD4+ lymphocyte count of $<200$ Cells $/ \mathrm{mm} 3$ were 2.9 times more likely to be coinfected than individuals who had CD4+ lymphocyte count of $\geq 350$ Cells $/ \mathrm{mm} 3$. A study conducted in Nigeria revealed similar finding where lower CD4+ lymphocyte count was observed in co-infected patients than mono infected patients [21]. Our study had also revealed a significant statistical association between WHO clinical stage and TB-HIV co-infection. Individuals who had a WHO clinical stage of IV were 8.6 times more likely to be co-infected compared to individuals who had a WHO clinical stage of III in crude analysis. Those patients with advanced WHO clinical stage had higher likelihood of having TB and other opportunistic infections as it is seen in CD4+ lymphocyte count.

Though it is not statistically significant, government employed individuals were $56 \%$ less likely to be coinfected compared to commercial sex worker. This could happen due to obvious reasons that commercial sex workers are liable for many opportunistic infections as an occupational risk. It needs great emphasis for prevention and interventional activities to reduce the burden of opportunistic infections and other complications associated with HIV/AIDS.

Our study included only pre-ART HIV positive patients which have relatively strong immunity compared to patients on ART. This needs great emphasis to avoid misapprehension by health professionals for early detection of opportunistic infections. Hence the main point of selecting only ART naïve patients in this study is to appreciate the value of close follow up of pre-ART patients to prevent early deterioration of patients by 
Table 3 Predictors of TB-HIV co-infection among study participants at University of Gondar Teaching Hospital, North West Ethiopia, 2011

\begin{tabular}{|c|c|c|c|c|c|}
\hline \multirow[t]{2}{*}{ Variables } & \multicolumn{2}{|c|}{ Pulmonary tuberculosis } & \multicolumn{2}{|l|}{ OR $(95 \% \mathrm{Cl})$} & \multirow[t]{2}{*}{$\mathrm{P}$ value } \\
\hline & Yes (TB-HIV) & No (HIV alone) & Crude & Adjusted & \\
\hline \multicolumn{6}{|l|}{ Age } \\
\hline $18-29$ & $10(7.8 \%)$ & $118(92.2 \%)$ & 1 & & \\
\hline $30-39$ & $9(5.4 \%)$ & $158(94.6 \%)$ & $0.67(0.265-1.706)$ & & \\
\hline $40-49$ & $9(11.5 \%)$ & $69(88.5 \%)$ & $1.54(0.596-3.973)$ & & \\
\hline 50 and above & $2(7.4 \%)$ & $25(92.6 \%)$ & $0.94(0.195-4.575)$ & & \\
\hline \multicolumn{6}{|l|}{ Sex } \\
\hline Male & $9(7.4 \%)$ & $113(92.6 \%)$ & 1 & & \\
\hline Female & $21(7.6 \%)$ & $257(92.4 \%)$ & $1.03(0.456-2.310)$ & & \\
\hline \multicolumn{6}{|l|}{ Residence } \\
\hline Urban & $28(8.4 \%)$ & 307 (91.6\%) & 1 & & \\
\hline Rural & $2(3.1 \%)$ & $63(69.9 \%)$ & $0.35(0.081-1.499)$ & & \\
\hline \multicolumn{6}{|l|}{ Marital status } \\
\hline Single & $8(10.7 \%)$ & $67(89.3 \%)$ & $1.16(0.329-4.119)$ & & \\
\hline Married & $10(5 \%)$ & 190 (95\%) & $0.51(0.153-1.720)$ & & \\
\hline Divorced & $8(9.8 \%)$ & $74(90.2 \%)$ & $1.05(0.299-3.721)$ & & \\
\hline Widowed & $4(9.3 \%)$ & $39(90.7 \%)$ & 1 & & \\
\hline \multicolumn{6}{|l|}{ Educational status } \\
\hline Illiterate & $10(6.6 \%$ & $141(93.4 \%)$ & $1.38(0.291-6.575)$ & & \\
\hline Elementary school & $12(12.5 \%)$ & $84(87.5 \%)$ & $2.79(0.595-13.05)$ & & \\
\hline High school & $6(5.4 \%)$ & $106(94.6 \%)$ & $1.10(0.214-5.701)$ & & \\
\hline Certificate and above & $2(4.9 \%)$ & 39 (95.1\%) & 1 & & \\
\hline \multicolumn{6}{|l|}{ Occupational status } \\
\hline Government employed & $4(6.9 \%)$ & $54(93.1 \%)$ & $0.44(0.073-2.713)$ & & \\
\hline Merchants & $6(14.3 \%)$ & $36(85.7 \%)$ & $1.00(0.178-5.632)$ & & \\
\hline Housewife \& daily laborer & $16(5.7 \%)$ & $263(94.3 \%)$ & $0.36(0.075-1.772)$ & & \\
\hline Students & $2(28.6 \%)$ & $5(71.4 \%)$ & $2.40(0.261-22.10)$ & & \\
\hline Commercial sex workers & $2(14.3)$ & $12(85.7 \%)$ & 1 & & \\
\hline \multicolumn{6}{|l|}{ WHO clinical stage $(n=72)$} \\
\hline Stage III & $21(34.4 \%)$ & $40(65.6 \%)$ & 1 & & \\
\hline Stage IV & $9(81.8 \%)$ & $2(18.2 \%)$ & $8.57(1.695-43.341)^{*}$ & & \\
\hline CD4+ Lymphocyte count & & & & & 0.042 \\
\hline$<200$ Cells/mm3 & $16(11.3 \%)$ & $126(88.7 \%)$ & $2.31(0.872-6.102)$ & $2.89(1.002-8.368)^{*}$ & \\
\hline 200-349Cells/mm3 & $8(5.6 \%)$ & $135(94.4 \%)$ & $1.08(0.363-3.196)$ & $1.19(0.378-3.726)$ & \\
\hline$\geq 350$ Cells/mm3 & $6(5.2 \%)$ & $109(94.8 \%)$ & 1 & 1 & \\
\hline
\end{tabular}

* Statistically significant (p-value $<0.05)$.

undetected opportunistic infections. Early detection of opportunistic infections including tuberculosis could be performed by lower level of health institutions including health extension workers involvement. This study was conducted at HIV/AIDS clinic and recruited those patients having regular follow up to imitate the situation present in the area. The limitation of this study is that laboratory diagnosis of $\mathrm{TB}$ was made only by $\mathrm{ZN}$ technique in addition to clinical and radiological investigations. Culture and molecular techniques were not used because of unavailability.

\section{Conclusion}

Higher prevalence of PTB was found in pre- ART HIV positive patients. Lower $\mathrm{CD} 4_{+}$lymphocyte count was found to be the only predicting factor for co-infection. 
Early detection of co-infection is very necessary to prolong their ART initiation time and by then strengthening their immune status. Further research both on ART and pre-ART patients is recommended to know the coinfection rate.

\section{Abbreviations}

AFB: Acid Fast Bacilli; AIDS: Acquired Immune Deficiency Syndrome; ART: Anti Retroviral Treatment; BD FACS: Becton Dickinson FluorescenceActivated Cell Sorting; CD4: Cluster of Differentiation; Cl: Confidence Interval; CXR: Chest X-Ray; EDTA: Ethylene Diamine-Tetra-acetic Acid; HIV: Human Immunodeficiency Virus; OR: Odds Ratio; PTB: Pulmonary Tuberculosis; SD: Standard Deviation; SPSS: Statistical Packages for Social Sciences; TB: Tuberculosis; WHO: World Health Organization; ZN: Ziehl-Neelson.

\section{Competing interests}

The authors declare that they have no competing interests.

\section{Authors' contributions}

YW: participated in conception and design of the study, data collection, analysis and interpretations of the findings, reviewed the manuscript. DM: participated in the design of the study, analysis and interpretations of the findings, drafting the manuscript and write up. YB: supervision of the study, analysis and interpretations of the findings, reviewed the manuscript. All authors reviewed and approved the final manuscript.

\section{Acknowledgements}

We acknowledge the technical support provided by Gondar University hospital. Our special thanks and appreciation also goes to all the study participants who voluntarily participate in this study. Lastly but not least, we also thank Gondar University hospital ART laboratory personnel for their consistent support with reagents and other materials during the project work.

\section{Author details}

'Department of Parasitology, School of Biomedical and Laboratory Sciences, College of Medicine and Health Sciences, University of Gondar, P.O. Box 196, Gondar, Ethiopia. ${ }^{2}$ Department of Medical Microbiology, School of Biomedical and Laboratory Sciences, College of Medicine and Health Sciences, University of Gondar, P.O. Box 196, Gondar, Ethiopia. ${ }^{3}$ Department of Immunology, School of Biomedical and Laboratory Sciences, College of Medicine and Health Sciences, University of Gondar, P.O. Box 196, Gondar, Ethiopia.

Received: 27 March 2012 Accepted: 14 June 2012

Published: 27 June 2012

\section{References}

1. WHO, UCSF: Report on HIV/AIDS in Ethiopia. CDC MMWR 2003, 52:217.

2. Harrington M: From HIV to Tuberculosis and Back Again: A Tale of Activism in 2 Pandemics. Clin Infect Dis 2010, 50:S260-\$266.

3. Friedland G, Churchyard GJ, Nardell E: Tuberculosis and HIV coinfection: current state of knowledge and research priorities. J Infect Dis 2007, 196:S1-S3.

4. Meya DB, McAdam KP: The TB pandemic: an old problem seeking new solutions. J Intern Med 2007, 261:309-329.

5. Girardi E, Raviglione MC, Antonucci G, Godfrey-Faussett P, Ippolito G: Impact of the HIV epidemic on the spread of other diseases: the case of tuberculosis. AIDS 2000, 14:3S47-3S56.

6. Sutherland I: Recent studies in the epidemiology of tuberculosis, based on the risk of being infected with tubercle bacilli. Adv Tuberc Res 1976, 19:1-63.

7. Vynnycky E, Fine PE: The natural history of tuberculosis: the implications of age-dependent risks of disease and the role of re-infection. Epidemiol Infect 1997, 119:183-201.

8. Bucher HC, Griffith LE, Guyatt GH, Sudre P, Naef M, Sendi P, Battegay M: Isoniazid prophylaxis for tuberculosis in HIV infection: a meta-analysis of randomized controlled trials. AIDS 1999, 13:501-507.

9. Selwyn PA, Hartel D, Lewis VA, Schoenbaum EE, Vermund ST, Klein RS, Walker AT, Friedland GH: A prospective study of the risk of tuberculosis among intravenous drug users with human immunodeficiency virus infection. N Engl J Med 1989, 320:545-550.

10. Girardi E, Raviglione MC, Antonucci G, Godfrey-Faussett P, Ippolito G: Impact of the HIV epidemic on the spread of other diseases: the case of tuberculosis. AIDS 2000, 14:S47-S56.

11. Lawn SD, Churchyard G: Epidemiology of HIV-associated tuberculosis. Curr Opin HIV AIDS 2009, 4:325-333.

12. Federal Ministry of Health (FMOH), HIV Prevention and Control Office: Single Point HIV Prevalence Estimate. Addis Ababa, Ethiopia: 2007. http://www. etharc.org/aidsineth/publications/singlepointprev.

13. Havlir DV, Barnes PF: Tuberculosis in patients with human immunodeficiency virus infection. N Engl J Med 1999, 340:367-373.

14. Jones BE, Young SM, Antoniskis D, Davidson PT, Kramer F, Barnes PF: Relationship of the manifestations of tuberculosis to CD4 cell counts in patients with human immunodeficiency virus infection. Am Rev Respir Dis 1993, 148:1292-1297.

15. Zumla A, Malon P, Henderson J, Grange JM: Impact of HIV infection on tuberculosis. Postgrad Med J 2000, 76:259-268.

16. World Health Organization: Global Tuberculosis control: Surveillance, planning and Financing:: 2008. http://www.who.int/tb/publications/global_report/en/_

17. Daniel WW: Biostatistics. A foundation for analysis in the Health Sciences. 8th edition. USA: Wiley International Edition; 2004.

18. International Union against Tuberculosis and Lung Disease: Sputum examination for tuberculosis by direct microscopy in low income countries. 5th edition. Paris: IUATLD; 2000.

19. BD FACS Count System User's Guide for Use with BD FACS Count CD4 Reagents; 2008. http://www.bdbiosciences.com/external_files/pm/doc/ manuals/live/web_enabled/339011.

20. Tuberculosis care with TB-HIV co-management: Integrated Management of Adolescent and Adult Illness.: 2007.

21. Iliyasu Z, Babashani M: Prevalence and Predictors of Tuberculosis Coinfection among HIV-Seropositive Patients Attending the Aminu Kano Teaching Hospital, Northern Nigeria. Epidemiology 2009, 19:81-87.

22. Ngowi BJ, Mfinanga SG, Bruun JN, Morkve O: Pulmonary tuberculosis among people living with HIV/AIDS attending care and treatment in rural northern Tanzania. BMC Publ Health 2008, 8:341.

23. Kimerling ME, Schuchter J, Chanthol E, Kunthy T, Stuer F, Glaziou P, Ee O: Prevalence of pulmonary tuberculosis among HIV-infected persons in a home care program in Phnom Penh, Cambodia. Int I Tuberc Lung Dis 2002, 6:988-994.

24. Awoyemi OB, Ige M, Onadeko BO: Prevalence of active pulmonary tuberculosis in human immunodeficiency virus seropositive adult patients in University College Hospital, Ibadan, Nigeria. Afr J Med Med Sci 2002, 31:329-332.

25. Rajasekaran S, Mahilmaran A, Annadurai S, Kumar S, Raja K: Manifestation of tuberculosis in patients with human immunodeficiency virus: A large Indian study. Ann Thorac Med 2007, 2:58-60.

26. Kassu A, Mengistu G, Ayele B, Diro E, Mekonnen F, Ketema D, Moges F, Mesfin T, Getachew A, Ergicho B, Elias D, Aseffa A, Wondmikun Y, Ota F: Coinfection and clinical manifestations of tuberculosis in human immunodeficiency virus-infected and -uninfected adults at a teaching hospital, northwest Ethiopia. J Microbiol Immunol Infect 2007, 40:116-122.

27. Swaminathan S, Padmapriyadarsini C, Narendran G: HIV-Associated Tuberculosis: Clinical Update. Clin Infect Dis 2010, 50:1377-1386.

doi:10.1186/1756-0500-5-331

Cite this article as: Wondimeneh et al:: Prevalence of Pulmonary tuberculosis and immunological profile of HIV co-infected patients in Northwest Ethiopia. BMC Research Notes 2012 5:331. 